\title{
Association between Friendship Quality and Depression Among High School Students in Jakarta
}

\author{
Umi Nur Kharimah $^{1}$, Wuri Prasetyawati ${ }^{2}$, Mita Puspita Sary ${ }^{3}$ \\ ${ }^{1,2,3}$ Faculty of Psychology, Universitas Indonesia, Depok, Indonesia
}

E-mail: uminkharimah16@gmail.com

\begin{abstract}
This study aims to investigate whether any correlation between friendship quality and depression among high school students in Jakarta. Friendship Quality Scale (FQS) and Hopkins Symptom Checklist 25 (HSCL-25) are used to measure friendship quality and psychological distress in the form of depressive symptoms. Participants of this study were 746 tenth graders from five high schools in Jakarta as an urban city. The result of this study shows that there is a significant difference in friendship quality between male and female adolescents, where female adolescents tend to have higher friendship quality compared to friendship among male adolescents. Contrary to findings from previous studies, this study shows a positive correlation between friendship quality and depression. This finding indicates higher friendship quality correlates with higher depressive symptoms, whereas lower friendship quality correlates with lower depressive symptoms among adolescents. Future research is needed to explore the dynamics of the positive correlation between friendship quality and depression.
\end{abstract}

Keywords: adolescents; depression; friendship quality; mental health; psychological distress

\section{Introduction}

School is a vital part of adolescents' life. Through school, adolescents gain opportunities to learn new skills and improve their existing skills (Papalia \& Martorell, 2014). A school is also a place where adolescents develop their cognitive abilities as well as broaden their social interactions through various activities, such as sports and arts activities. Regarding social interactions, adolescents who have positive interactions with teachers, friends, and other members in school potentially enhance their social skills, form a stronger bond and sense of belongingness, and make them feel cared at the same time. Adolescents also can start to plan their future career during school (American Psychological Association, 2002).

Unfortunately, school is also a primary source of stress among adolescents (Palmiter \& Wilson, n. d.). Adolescents who often exposed to stressors, such as school tasks, exams, school rules, or interpersonal problems with friends and teachers, could trigger the onset of depression symptomatology (DeLongis, Coyne, Dakof, Folkmanm, \& Lazarus, 1983, in Allgood-Merten, Lewinsohn, \& Hops, 1990). There are also risk factors increasing the tendency of adolescents and emerging adults to suffer from depression, such as gender, psychosocial, and family or genetics factors (Moreh \& O'Lawrence, 2016).
The prevalence of depression among adolescents shows an increasing trend (Papalia \& Martorell, 2014). Several studies found that adolescents are vulnerable to suffer from depression (Lewinsohn et al., 1993; Roberts et al., 1990). It is estimated that $4-8 \%$ of the world population of adolescents suffer from depression (Sabaté, 2004). In 2016, the Directorate of Prevention and Control of Mental Health and Drug Problems, Ministry of Health of Republic of Indonesia, did a screening to 1,300 high school students in South Jakarta and found that 30 percent of students potentially suffered from depression (Sukmasari, 2016). In 2014, there were at least five high school students in Jember, East Java, had to meet therapist because of depression due to national examination (Tempo, 2014).A high school student in Riau consumed laundry bleaching liquid because of depression (Riau Global, 2015).

Adolescents often spend their time in school. Some factors related to school context could become risk factors, such as academic self-concept, parents' dissatisfaction of academic performance perception, and anxiety due to test or exam (Lee, Wong, Chow, \& McBride-Chang, 2006), and other things related to school life, such as interpersonal relationship with teachers, friends, and school climate (Drew, 2012) are 
associated with depression. Therefore, depression in adolescence could be related to the school context.

Urban area, including Jakarta, is considered to become one of many factors that increase the adolescents' risk to suffer from psychological distress, particularly depression symptomatology. According to a study by Romans, Cohen, and Forte (2011), people who live in the big city or urban area have higher depression level compared to people in the rural area. Higher depression among people who live in the urban area is caused by risky and full of pressure environment (Paykel, Abbott, Jenkins, Brugha, \& Meltzer, 2000), such as poverty in the city, rapid mobility, high population density, and severe traffic jam in Jakarta. Besides, in the urban area, community interactions are declining and socially isolated (Mueller, 1981, in Wang, 2004). For adolescents who live in Jakarta, this condition might be detrimental to adolescents' mental health due to their still-developing coping ability (Compas, 1998).

Depressive adolescents characterized by having interpersonal impairments notably their interactions with friends (American Academy of Child \& Adolescent Psychiatry, 2013), academic problems, delinquency behaviors, drugs intake, suicide ideation, and highly related to other psychosocial characteristics, such as lack of social support from family members and friends (Lewinsohn, Roberts, Seeley, Rohde, Goltih, \& Hops, 1994). Among these characteristics, interpersonal impairments with friends considered as the most influencing factors because they spend a lot of time with friends more than with parents or siblings (American Psychological Association, 2002).

Friendship in adolescence has an important role in development (Stone, 2013), it helps adolescents to construct identity (Papalia \& Martorell, 2014). Increasing intimacy in adolescents' friendship is followed by increasing cognitive and emotional ability related to psychological adjustment and social competence (Papalia \& Martorell, 2014). Adolescents start to improve morale and value judgment because of friendship (Bishop \& Inderbitzen, 1995). Friendship also acts as a source of information about the outside world (Santrock, 2001, in American Psychological Association, 2002). Furthermore, adolescents are more dependent on their friends rather than their parents for intimacy, support, and trust (Hartup \& Stevens, 1999; Nickerson \& Nagle, 2005, in Papalia \& Martorell, 2014). Friendship quality could determine adolescents' success in the social relationship, especially with peers (Berndt, 2002), and intimacy could influence psychological adjustment and social competence (Papalia \& Martorell, 2014).
According to a study by Buck and Dix (2012), friendship quality mediates the relationship between inhibition and depression symptoms. Inhibition increases conflict, while conflict decreases support and positive affect to friends among adolescents. Parker and Asher (1993) reported that positive affect in friendship quality characterized with care, support, and interest towards each other. Friendship quality has been found to correlate with adolescents' popularity in peers that contributed to loneliness and social dissatisfaction (Parker \& Asher, 1993) and implies decreasing of mental health. Another study found that friendship has relation with depression mediated by loneliness (Nangle, Erdley, Newman, Mason, \& Carpenter, 2003). Adolescents who have close, stable, and supporting friendship tend to have fewer interpersonal conflicts and lower level of anxiety as well as depression (Berndt \& Perry, 1990, in Papalia \& Martorell, 2014). In contrast, a study by van Voorst (2015) did not found a significant correlation between positive friendship quality and depression symptomatology.

Previous studies show inconclusive findings of gender differences in friendship quality affecting depression among adolescents. A study by Siegel (2004) found that friendship quality has a significant correlation with depression symptomatology among female, but not among male, due to the difference in friendship quality among males and females. Specifically, the female tends to prefer harmonious interactions, whereas male show more confrontation behaviors (Markievicz, Brendgen, Markiewicz, Doyle, \& Bukowski, 2001). Buhrmenster and Furman (1987, in Markievicz, Brendgen, Markiewicz, Doyle, \& Bukowski, 2001) explained the differences between friendship quality perceived by female and male, where some aspects of friendship quality are naturally stronger in female than male.

Drawing from existing literature, the researcher examined the relationship between friendship quality and depression among high school students in Jakarta, known as an urban area. The researcher hypothesizes that there is a significant relationship between friendship quality and depression among high school students.

\section{Methods}

Sample. Participants are 746 (46.9\% male, 53.1\% female) of the tenth graders of high school students from five high schools located in five urban areas in Jakarta.

Research Design. This research is a cross-sectional study. 
Measurement. This research used two questionnaires: Friendship Quality Scale (FQS) (Bukowski, Hoza, \& Boivin, 1994) to measure friendship quality for adolescents by measuring five aspects: companionship, conflict, help, security, and closeness, and Hopkins Symptom Checklist 25 (HSCL-25) (Derogatis, Lipman, Rickels, Uhlenhuth, \& Covi, 1974) to measure depression symptomatology. FQS's items are commonly statements about how meaningful adolescents with their friends in five points Likert scale, ranged from 1 (definitely not true) to 5 (definitely true) with the items are mentioned like, "if I have a problem at school or at home I can talk to my friend about it' and 'if other kids were bothering me my friend would help me'. While HSCL-25's items are commonly a list of statements about depressive symptoms like 'lost appetite', 'feel lonely', and 'do not have any interest in things', and the participants have to choose from four points Likert scale ranged from definitely not bothering to definitely bother. HSCL-25 measures psychological distress through depression and anxiety, the items used in this research are items number 11 to 25 which specifically measure depression. According to try out, FQS's Cronbach's Alpha coefficient was 0.86, whereas the HSCL-25 Cronbach's Alpha coefficient was 0.90 for the total score, 0.85 for the depression subscale, and 0.76 for the anxiety subscale (in Glaesmer, Braehler, Grande, Hinz, Petermann, \& Romppel, 2014). FQS's score is obtained through the calculation of each participant's average from 23 items, while HSCL-25's score is obtained through the calculation of the average from 15 items which are measuring depression symptomatology. HSCL25 has cutoff score 1.75 for categorizing the level of depressive symptomatology, which means that the scores below to 1.75 are categorizing as a low level of depressive symptoms, whereas scores above or equal to 1.75 are categorizing as a high level of depressive symptoms. This study used descriptive analysis and Pearson analysis to examine the correlation between two variables.

Procedure. Five high schools were chosen to be participants, represent five urban areas in Jakarta selected by random sampling method. Each school represents for each urban area in Jakarta: North Jakarta, East Jakarta, South Jakarta, West Jakarta, and Central Jakarta. The participants are all of the tenth graders in each school. We obtained permission from each school after setting up a series of meetings with the headmasters of five schools. These series of meetings aim to help the schools to fully understand about this study. After we got the permissions and made an appointment with the schools, we prepared the questionnaire booklets and rewards for each school as well. We also asked for permission by using informed consent signed by the headmaster before we collected the data. The data collection process carried out in classical manners, where we administered the questionnaires in each classroom ranging from 25 to 45 students. Before we started the data collection process, the researcher team provided a brief explanation about this study for the students. We also asked the students whether they would become a participant or not. If they did not want to get involved in the research, we allowed them to go outside the classroom. After we instructed to answer the questionnaires in front of the class, we gave them a questionnaire booklet and a pen for each student. The students needed around 25 to 45 minutes to finish the questionnaire. After completing and collecting all questionnaires, we gave them a small token consist of notebook and snacks. Last, the research team thanked all the students and left the classroom.

\section{Results}

Descriptive Data. Participants of this research included 746 (46.9\% male, $53.1 \%$ female) tenth graders of high school students in Jakarta. Based on the schools' location, North Jakarta has 107 students (5.8\% male, $8.6 \%$ female), East Jakarta has 208 students (13.9\% male, $13.9 \%$ female), South Jakarta has 108 students (7.0\% male, $7.5 \%$ female), West Jakarta has 210 students $(11.5 \%$ male, $16.6 \%$ female), and Central Jakarta has 113 students (8.7\% male, $6.4 \%$ female) as the participants of this study. The ages of the participants are ranging from 14 to 19 years old.

Table 1

Depressive Symptoms Categorization

\begin{tabular}{cc}
$\begin{array}{c}\text { Depressive Symptoms } \\
\text { Level }\end{array}$ & $\boldsymbol{N}$ \\
\hline Low & $133(17.83 \%)$ \\
High & $613(82.17 \%)$ \\
Total & $746(100 \%)$ \\
\hline
\end{tabular}

According to Table 1., there are 133 participants (17.83\%) who have low depressive symptoms and 613 participants $(82,17 \%)$ who have high depressive symptoms. 
Table 2.

Common Information about Friendship Quality and Depression Scores

\begin{tabular}{ccccccc}
\hline \multirow{2}{*}{ Variables } & \multicolumn{2}{c}{ Male } & \multicolumn{2}{c}{ Female } & \multicolumn{2}{c}{$\begin{array}{c}\text { Independent } \\
\text { sample t-test }\end{array}$} \\
\cline { 2 - 7 } & Mean & SD & Mean & SD & $\boldsymbol{t}$ & $\boldsymbol{p}$-value \\
\hline Friendship quality & 3.40 & 0.5 & 3.76 & 0.5 & $-9,532$ & 0,000 \\
Companionship & 3.44 & 0.8 & 3.79 & 0.8 & $-5,868$ & 0,000 \\
Conflict* & 2.95 & 0.9 & 2.89 & 0.9 & 0,911 & 0,362 \\
Help & 3.52 & 0.8 & 3.98 & 0.8 & $-7,803$ & 0,000 \\
Security & 3.54 & 0.7 & 3.98 & 0.6 & $-8,866$ & 0,000 \\
Closeness & 3.49 & 0.8 & 4.01 & 0.7 & $-9,749$ & 0,000 \\
Depression & 2.39 & 0.7 & 2.49 & 0.7 & $-2,025$ & 0,043 \\
\hline *aspect has reversed items & & & & & &
\end{tabular}

According to Table 2., friendship quality score is higher in female than male $(t=-9.532, p<0.01)$. Depression score is also higher in female than male $(t=-2.025, p<0.05)$.

Table 3.

Correlation between Friendship Quality and Depression

\begin{tabular}{ccc}
\hline \multirow{2}{*}{ Variables } & \multicolumn{2}{c}{ Depression } \\
\cline { 2 - 3 } & $\boldsymbol{r}$ & $\boldsymbol{p}$-value \\
\hline Friendship quality & 0.075 & 0.042 \\
Companionship & 0.115 & 0.002 \\
Conflict* & -0.194 & 0.000 \\
Help & 0.108 & 0.003 \\
Security & 0.079 & 0.030 \\
Closeness & 0.129 & 0.000 \\
\hline
\end{tabular}

This research used Pearson correlation to analyses the correlation between friendship quality and depression. According to Table 3., there is a significant correlation between friendship quality and depression $(r=0.075, p<0.05)$. The positive $r$ score shows that the correlation is positive which indicates high friendship quality correlates to high depression level and low friendship quality correlates to low depression level. The table also shows the correlation between five aspects of friendship quality and depression. All aspects are significantly correlated with depression $(p<0.05)$, but only conflict has negative correlation $\left(r_{\text {confict }}=-\right.$ 0.194) while others have positive correlation with depression $\left(r_{\text {companionship }}=0.115, r_{\text {help }}=0.108, r_{\text {security }}=\right.$ $\left.0.079, r_{\text {closeness }}=0.129\right)$. The higher score in conflict aspect shows the higher conflict solved in friendship.

\section{Discussion \& Conclusion}

Discussion. Friendship quality is a degree how meaningful the friendship characterized by the level of the aspects of friendship (Parker \& Asher, 1993; Berndt, 2002; Berndt, 1996, in Phebe, 2007). Berndt (2002) explained that a good friendship is characterized by high prosocial behavior, close relationship, and other positive aspects and also lower of conflict, rivalry, and other negative aspects.
Based on the findings of this study, there is a significant positive correlation between friendship quality and depression among adolescents. This result is different to previous studies which showed that low friendship quality is related with loneliness and increase depression symptoms (Parker \& Asher, 1993), or low friendship quality indirectly related to depression symptomatology mediated by inhibition (Buck \& Dix, 2012). A study by Siegel (2004), also found a negative correlation between friendship quality and depression symptomatology among female. Differently, this research is showing that there is a significant positive correlation between friendship quality and depression among male and female. It shows that high friendship quality correlated with high depression and low friendship quality correlated with low depression among adolescents.

According to friendship quality's aspects and their correlation to depression score, found that positive aspects including companionship, help, security, and closeness positively correlate to depression score. The high scores on positive aspects of friendship quality are probably caused by the strong friendship influence in adolescence compared with previous stages (Papalia \& Martorell, 2014), and it has naturally occurred during the development task in adolescents. The increase score of depression among adolescents is potentially caused by more challenges in teen life compared to their previous developmental stages. (Nolen-Hoeksema \& Girgus, 1994).

Another explanation for the contrary findings with previous studies is related to research by Ross and Mirowsky (1989) and Rose (2002). High friendship quality, characterized by high intimacy, implies the tendency to tell the problems to other people (Ross \& Mirowsky, 1989) and it would make adolescents more conscious of their problems (Rose, 2002). Furthermore, adolescents perceive their friends as a primary source of affection and support (Papalia \& Martorell, 2014). According to Ross et al. (1989) and Rose (2002), telling the problems to others associated with the rising of depression. People who 
often tell their problems tend to have a close relationship with people who listen to the story about their problems which make them aware of the emotional condition, trying to recall other things related to the problems, and tend to tell them (Ross \& Mirowsky, 1989; Rose, 2002). Telling problems often strengthen the feeling of guilt, uncertainty, unfairness, and other things lead to depression. In adolescence, friendship has a primary role in its development. They tend to seek support and ask suggestion from friends (Parker \& Asher, 1988, in Phebe, 2007) because they perceive friend is a source of affection and sympathy, and also as moral guidance (Papalia \& Martorell, 2014). Therefore, there is a probability that adolescents would tell their close friends about their problems, and it would lead to increase their depression level. Further research is needed to investigate this possible mechanism.

In the conflict aspect, there is a significant negative correlation that shows the high score of conflict correlate to low depression score, (conflict score is reversed score). Conflict score shows how a friendship could solve adolescents' problems; the higher score shows a better friendship in solving problems. A negative correlation between conflict and depression could explain the high score of depression symptomatology in this research. A study by van Voorst (2015), found that negative friendship quality has a strong correlation with depression. In this study, the negative aspect of friendship quality is showed by conflict aspect. Negative aspect of friendship quality is a better predictor of social well-being compared to positive friendship quality. It shows that adolescents who suffer from depression perceive their friendship more negatively and positive friendship quality could not protect from depression symptomatology (van Voorst, 2015). Besides, the strong correlation between the negative aspect of friendship quality and depression could be explained by the theory of negativity effect model (Ingersoll-Dayton, Morgan, \& Antonucci, 1997). According to the theory of negativity effect model, the negative exchange is strongly related to negative effect compared to positive exchange (Ingersoll-Dayton, Morgan, \& Antonucci, 1997). It shows that there is a difference between positive aspect and negative aspect of friendship quality and its correlation on depression in adolescents.

Conclusions. This research shows contradictive result compared to previous studies. But this research also found that negative aspect of friendship quality negatively correlates to depression, contradictory with the correlation between positive aspects of friendship quality. This finding shows that having high positive aspects of friendship quality would not keep the depressive symptoms away. Further research is needed to explore more about positive and negative aspects of friendship quality and their correlation to depression among adolescents and hopefully, there would be other research that could explain better about depression among adolescents in Jakarta.

\section{References}

Allgood-Merten, B., Lewinsohn, P. M., \& Hops, H. (1990). Sex differences and adolescent depression. Journal of Abnormal Psychology, 99(1), 55-63.

American Academy of Child \& Adolescent Psychiatry. (2013). Depression in children and teens. American Academy of Child \& Adolescent Psychiatry. Retrieved on February 5, 2017, from https://www.aacap.org/AACAP/Families_and_Youth/F acts_for_Families/FFF-Guide/The-Depressed-Child004.aspx

American Psychiatric Association. (2013). Diagnostic and statistical manual of mental disorders (5th ed.). Washington, DC: Author.

American Psychological Association. (2002). A reference for professionals: Developing Adolescents. Washington, DC: Author.

Berndt, T. J. \& Perry, T. B. (1986). Children's perceptions of friendships as supportive relationships. Developmental Psychology, 22(5), 640-648.

Berndt, T. J. (1982). The features and effects of friendship in early adolescence. Child Development, 53, 1447-1460.

Berndt, T. J. (2002). Friendship quality and social development. American Psychological Society, 11(1), 7-10.

Bishop, J. A. \& Inderbitzen, H. M. (1995). Peer acceptance and friendship: An investigation of their relation to selfesteem. Journal of Early Adolescence, 15(4), 476-489.

Buck, K. A. \& Dix, T. (2012). Can developmental changes in inhibition and peer relationships explain why depressive symptoms increase in early adolescence? Journal Youth Adolescence, 41, 403-413.

Bukowski, W. M., Hoza, B., \& Boivin, M. (1994). Measuring friendship quality during pre- and early adolescence: The development and psychometric properties of the friendship qualities scale. Journal of Social and Personal Relationships, 11, 471-484.

Compas, B. E. (1998). An agenda for coping research and theory: Basic and applied development issues. International Journal of Behavioral Development, 22(2), 231-237.

Derogatis, L. R., Lipman, R. S., Rickels, K., Uhlenhuth, E. H., \& Covi, L. (1974). The Hopkins Symptom Checklist (HSCL): A self-report symptom inventory. Behavioral Science, 19.

Drew, H. L. (2012). A multilevel analysis of the association between school climate dimensions and adolescent depressive symptoms using the ecological perspective (Order No. 3529793). Retrieved from ProQuest

Glaesmer, H., Braehler, E., Grande, G., Hinz, A., Petermann, F, \& Romppel, M. (2014). The German version of the Hopkins Symptoms Checklist-25 (HSCL-25): Factorial structure, psychometric properties, and populationbased norms. Comprehensive Psychiatry, 55(2), 396403. 
Ingersoll-Dayton, B., Morgan, D., \& Antonucci, T. (1997). The effects of positive and negative social

Lee, M. T. Y., Wong, B. P., Chow, B. W., \& McBride-Chang, C. (2006). Predictors of suicide ideation and depression in Hong Kong adolescents: Perceptions of academic and family climates. Suicide and Life-Threatening Behavior, 36(1), 82 .

Lewinsohn, P. M., Hops, H., Roberts, R. E., Seeley, J. R., \& Andrews, J. A. (1993). Adolescent psychopathology: I. Prevalence and incidence of depression and other DSMIII-R disorders in high school students. Journal of Abnormal Psychology, 102, 133-144.

Lewinsohn, P. M., Roberts, R. E., Seeley, J. R., Rohde, P., Gotlib, I. H., \& Hops, H. (1994). Adolescent psychopathology: II. Psychosocial risk factors for depression. Journal of Abnormal Psychology, 103(2), 302-315.

Markievicz, D., Brendgen, M., Markiewicz, D., Doyle, A. B., \& Bukowski, W. M. (2001). The relations between friendship quality, ranked-friendship preference, and adolescents' behavior with their friends. Merrill-Palmer Quarterly, 47(3), 395-415.

Mirowsky, J. \& Ross, C. E. (1986). Social patterns of distress. Annual Review of Sociology, 12, 23-45

Moreh, S., \& O'Lawrence, H. (2016). Common risk factors associated with adolescent and young adult depression. Journal of Health and Human Services Administration, 39(2), 283-310.

Nangle, D. W., Erdley, C. A., Newman, J. E., Mason, C. A., \& Carpenter, E. M. (2003). Popularity, friendship quantity, and friendship quality: Interactive influences on children's loneliness and depression. Journal of Clinical Child \& Adolescent Psychology, 32(4), 546-555.

Nolen-Hoeksema, S. \& Girgus, J. S. (1994). The emergence of gender differences in depression during adolescence. Psychological Bulletin, 115(3), 424-443.

Palmiter, D. J. \& Wilson, D. (n. d.). Teens and stress: How to keep stress in check. American Psychological Association. Retrieved on February 5, 2017, from http://www.apa.org/helpcenter/stress-teens.aspx

Papalia, D. E. \& Martorell, G. (2014). Experience human development (13th ed.). New York: McGraw-Hill.

Parker, J. G. \& Asher, S. R. (1993). Friendship and friendship quality in middle childhood: Links with peer group acceptance and feelings of loneliness and social dissatisfaction. Developmental Psychology, 29(4), 611621.

Paykel, E. S., Abbott, R., Jenkins, R., Brugha, T. S., \& Meltzer, H. (2000). Urban-rural mental health differences in Great Britain: Findings from the national morbidity survey. Psychological Medicine, 30, 269-280.

Phebe, L. F. W. (2007). Peer relations in preadolescence: Associations between friendship quality, peer acceptance, and parental management in peer relations. Retrieved from http://lbms03.cityu.edu.hk/oaps/ss20075790-lfw768.pdf.

Riau Global (2015, November 24). Depresi siswa SMA tenggak cairan pemutih pakaian. Global Riau. Retrieved on February 5 2017, from http://www.riauglobal.com/read-7381-2015-11-24-depresi-siswa-smatenggak-cairan-pemutih-pakaian.html.

Roberts, R. E., Andrews, J. A., Lewinsohn, P. M., \& Hops, H. (1990). Assessment of depression in adolescents using the Center for Epidemiologic Studies of Depression Scale. Psychological Assessment, 2, 122-128.
Romans, S., Cohen, M., \& Forte, T. (2011). Rates of depression and anxiety in urban and rural Canada. Social Psychiatry and Psychiatric Epidemiology, 46, 567-575.

Rose, A. J. (2002). Co-rumination in the friendships of girls and boys. Child Development, 73(6), 1830-1843.

Ross, C. E. \& Mirowksy, J. (1989). Explaining the social patterns of depression: Control and problem solvingor support and talking? Journal of Health and Social Behavior, 30, 206-219.

Ross, C. E., Mirowsky, J., \& Cockerham, W. C. (1983). Social class, Mexican culture, and fatalism: Their effects on psychological distress. American Journal of Community Psychology, 11(4).

Sabaté, E. (2004). Priority medicines for Europe and the world "A public health approach to innovation": Depression in young people and the elderly. Background Paper.

Siegel, L. R. (2004). Peer group experiences, friendship quality, and depressive symptomatology in adolescence: $A$ longitudinal analysis (Order No. 3128574). Retrieved from ProQuest Dissertations \& Theses Global (305132857)

Stone, L. B. (2013). Risk for adolescent depression: Gender differences and contagion in peer networks (Order No. 3590905). Retrieved from ProQuest Dissertations \& Theses Global (1432195996).

Sukmasari, R. N. (2016, Oktober 11). Dari skrining 1300 siswa SMA di Jakarta Selatan 30 persen berpotensi depresi. Detik Health. Retrieved on January 20 2017, from http://health.detik.com/read/2016/10/11/120206/331780 7/763/dari-skrining-1300-siswa-sma-di-jaksel-30persen-berpotensi-depresi

Tempo (2014, April 14). Gara-gara UN lima siswa di Jember depresi. Tempo. Retrieved on February 5 2017, from https://m.tempo.co/read/news/2014/04/14/079570634/g ara-gara-un-lima-siswa-di-jember-depresi.

Thien, L. M., Razak, N. A., \& Jamil, H. (2012). Friendship quality scale: Conceptualization, development, and validation. Australian Association for Research in Education.

Van Voorst, C. (2015). The effect of negative and positive friendship quality on depressive symptoms in adolescents and the role of loneliness. Retrieved from http://arno.uvt.nl/show.cgi?fid=136691.

Wang, J. L. (2004). Rural-urban differences in the prevalence of major depression and associated impairment. Social Psychiatry and Psychiatric Epidemiology, 39, 19-25.

World Health Organization. (2017). Media centre: Depression. World Health Organization. Retrieved on Mei 5 2017, from http://www.who.int/mediacentre/factsheets/fs369/en/ 